\title{
EDITORIALS
}

\section{Keeping Up with Survivors: Education Across the Spectrum of Cancer}

\author{
Jennifer Potter, $M D^{7}$ and Katherine Johnston, MD, MA, MSc ${ }^{2}$ \\ 'Harvard Medical School, Women's Health Center, Beth Israel Deaconess Medical Center, Boston, MA, USA; ${ }^{2}$ Harvard Medical School, Beth \\ Israel Deaconess Medical Center, Boston, MA, USA.
}

J Gen Intern Med 24(Suppl 2):501-2

DOI: $10.1007 / \mathrm{s} 11606-009-1066-\mathrm{x}$

(c) Society of General Internal Medicine 2009

$\mathrm{T}$ he Institute of Medicine (IOM) report: From Cancer Patient to Cancer Survivor: Lost in Transition, ${ }^{1}$ clearly articulated a need for cancer education programs addressing survivorship. Even earlier in the 1980's, the American Association of Cancer Education (AACE) recommended improving cancer education in United States medical schools. ${ }^{2}$ Disappointingly, a follow-up survey done a decade later demonstrated little progress. ${ }^{3} \mathrm{AACE}$ recommendations included a national cancer education curriculum; improved instructional materials, methods and evaluation tools; and an ongoing funding process to provide support for educational activities, with a shift in emphasis to include more on topics of prevention, early diagnosis, tumor biology, rehabilitation, palliative care and psychosocial issues. ${ }^{4}$

The need for a national cancer education curriculum continues to grow as the number of cancer survivors increases and oncology clinics have difficulty providing access to new patients. Clinical and educational models would do well to adapt to these changes with a significant paradigm shift. Instead of being viewed as a discrete event in a person's life, cancer is now understood to be a waxing and waning chronic illness that creates a spectrum of exposures and experiences that must be addressed longitudinally in order to optimally manage each survivor's needs at different points across the spectrum of care. The traditional illness- and anatomy-based approach to cancer education results in failure to address overarching themes that pertain to all cancer survivors. Education should incorporate the importance of sensitive communication and psychosocial support, a focus on rehabilitation and function, consideration of secondary prevention and how to sustain a sense of wellbeing in the context of dealing with chronic illness. Similarly, traditional delivery of health professions training in discipline-specific silos means that we lose the opportunity to integrate knowledge and skills that accumulate across disciplines. We believe that in order to successfully address the full scope of survivors' needs, educators must embrace a new educational standard that values the voices of all stakeholders, including cancer survivors themselves, as well as learners and teachers from diverse disciplines. Care of cancer survivors is by its very nature multidisciplinary and is provided most effectively using a team approach: survivorship education initiatives should therefore be designed in a similar manner.
While we cannot comprehensively review survivorship education programs, several educational models illustrate key points. The article by Uijtdehaage and colleagues in this issue of JGIM ${ }^{5}$ provides an update on work that began almost ten years ago as a multidisciplinary cancer education curriculum for medical students created with support from the National Cancer Institute (NCI). Using a stepwise process, a consensus panel developed clearly articulated learning objectives to guide curricular revision; ${ }^{6}$ a curriculum task force worked with course directors to develop or revise instructional materials; and a 28-hour enhanced curriculum was rolled out across years 1-3 of medical school. ${ }^{7}$ Content focused on identifying risk factors and counseling for lifestyle change in the 1st year, pathophysiology (carcinogenesis and women's cancer risks) in the 2nd year, and skills development (skin and prostate exams, family counseling on breast cancer risk) in the 3rd year. Teaching methods included lectures, problem based learning cases, standardized patient exercises, and computer simulations. Knowledge acquisition was tested using multiple choice tests; counseling and screening skills were assessed by student self-report. Students' scores in each of these areas increased progressively with each level of training, but were most pronounced in the $3^{\text {rd }}$ (clerkship) year. Interestingly, self-reported counseling skills increased significantly from baseline to year 1 and between year 2 to year 3 but not between years 1 and 2 . The authors attributed this difference to use of more traditional teaching approaches and an emphasis on pathophysiology during the 2nd year, and stress the importance of using instructional methods that offer students handson opportunities to practice skills. Others have previously noted the utility of introducing communication concepts early in training, when learners are most malleable, followed by repetition of the message and ongoing opportunities to practice skills so they do not atrophy over time ${ }^{8}$.

This group went on to collaborate with two other institutions to develop and evaluate an expanded version of the original curriculum in three different settings, as Uijtdehaage and colleagues describe elegantly. Their experience suggests a curricular development framework: incorporating clearly articulated learning objectives that encompass survivorship themes; use of modular educational units that employ a variety of educational methods and facilitate integration of new content into the existing curriculum; and development of a validated assessment tool to measure outcomes. Many of these materials can be downloaded from the UCLA Cancer Survivorship website. ${ }^{9}$ Compared to historical controls who did not receive the survivorship curriculum, 4th year medical students increased their knowledge regarding survivorship issues and comfort dealing with cancer survivors. However, while post-intervention knowledge scores increased significantly in two of the institutions, students at the 
3rd institution, where fewer modules were implemented, did not demonstrate such knowledge gain. This variation underscores the need to test educational interventions in multiple settings to prove that their benefits can be replicated, as unique challenges to successful implementation are often encountered in different venues. Moreover, as the authors themselves note, additional work needs to be done to assess whether enhanced knowledge and comfort translate into improvements in actual survivorship care-outcomes that were not tested in their study as they did not objectively examine acquisition or retention of skills.

Other curriculum development efforts focus on improving continuing medical education (CME). One, sponsored by the City of Hope National Medical Center and also funded by the NCI, utilizes a multidisciplinary "train the trainer" model to impact educational changes and delivery of care at the institutional level. ${ }^{10}$ This project will eventually enroll teams of two professionals from over 50 medical institutions nationwide in an intensive, three-day training program in cancer survivorship, during which participants are expected to develop specific goals to lead new survivorship activities in their own institutions. Course content was developed using a quality of life model created by the National Coalition for Cancer Survivorship ${ }^{11}$ and evidence-based content in the aforementioned IOM report. To increase the likelihood that learning results in organizational change, participants are selected based on qualifications and projected goals; letters of commitment from two hospital administrators at their home institutions are required; and specific lectures on how to change practice via performance improvement are included in the curriculum. The entire initiative is based on principles of adult learning, requiring active engagement of participants using interactive and problem-based methods, and frequent assessment of changes in knowledge, behavior or activities resulting from the course. Preliminary evaluation of the 1st year of the project demonstrates enrollment of team members from a variety of disciplines and positive course evaluations; a list of goals has been compiled that will be used to evaluate progress implementing course content at their home institutions.

Clearly, no one educational strategy can be successful with all learners and in every setting: a multifaceted approach is needed. However, given financial constraints, it will be exceedingly helpful if we can share our successes by publicizing educational content and housing "stand-alone" educational interventions in curricular repositories such as Health Education Assets Library ${ }^{12}$ and the American Association of Medical Colleges MedEd Portal, ${ }^{13}$ where they will be available for educators everywhere to adapt and use for their own purposes. There is general agreement regarding the optimal content that should be included in a comprehensive oncology curriculum that encompasses cancer survivorship, and several professional organizations have published lists of core concepts. ${ }^{14-16}$

Where should we go from here? We face numerous challenges- a vast and expanding body of knowledge; competition for curricular time; a shift in teaching from inpatient to outpatient settings; clinical productivity expectations that erode availability of teaching faculty and limit CME opportunities; and sparse recognition and support of medical education initiatives relative to medical research and patient care. Cancer survivorship education is still in its infancy: additional work is urgently needed to develop, assess and disseminate innovative educational modalities. Given the burgeoning numbers of cancer survivors today, we support education for all health professionals who care for or will encounter cancer survivors in the course of their practice, rather than narrowly focused efforts targeted exclusively toward oncology specialists or boutique providers. Curricular change will be facilitated if national standards of care are clearly articulated, educational interventions that convey key concepts are woven into existing curricula, and competency must be demonstrated in order to graduate or remain licensed. We urge grantors to support survivorship education proposals that incorporate a multidisciplinary design; include a rigorous evaluation component; and are feasible to implement and sustain, portable to a variety of learning venues, and amenable to continuous refinement as our knowledge about the needs of cancer survivors advances.

Corresponding Author: Jennifer Potter, MD; Harvard Medical School, Women's Health Center, Beth Israel Deaconess Medical Center, 330 Brookline Avenue, Boston, MA 022125, USA (email: jpotter@bidmc.harvard.edu).

\section{REFERENCES}

1. Hewitt M, Greenfield S, Stovall E, eds. From Cancer Patient to Cancer Survivor: Lost in Transition. Washington, DC: National Academies Press; 2006.

2. Bakemeier RF, Wood DA, Vaitkevicius VK, Mozden PJ, Miller AS, Mellette SJ, Hall LR. Cancer Education Survey. Vols 1-6. Publications No. 81-2255 to 81-2260. Washington, DC: US Dept. of Health and Human Services; 1981

3. Chamberlain RM, Bakemeier RF, Gallagher RE, Kupchella CE, O'Donnell JF, Parker J, Hill GJ, Brooks CM. Cancer prevention education in United States medical schools. Cancer Education Survey II. J Cancer Educ. 1992;7:105-14.

4. Bakemeier RF, Kupchella CE, Chamberlain RM, Gallagher RE, O'Donnell JF, Parker JA, Hill GJ, Brooks CM. Survey design and observations relating to cancer education funding. $J$ Cancer Educ. 1992; 7:85-93.

5. Uijtehaage et al article in this issue of JGIM.

6. Stuber ML, Guiton G, Wilkerson L. Cancer as a chronic illness: competencies for a curriculum for medical students. J Cancer Educ. 2003; $18: 23$.

7. Wilkerson L, Lee M, Hodgson CS. Evaluating curricular effects on medical students' knowledge and self-perceived skills in cancer prevention. Acad Med. 2002;77(10 Suppl):S52-3.

8. Barrier JH, Brazeau-Lamontagne L, Pottier P, Boutoille D. Comparison of medical ethical competencies of pregraduate third and sixth year students during their internal medical hospital rotations. Rev Med Intern. 2005;26: 128-36

9. UCLA Cancer Survivorship website. Available at: http://www.medsch. ucla.edu/cancersurvivorship/downloads.htm. Accessed July 2009.

10. Grant M, Economou D, Ferrell B, Bhatia S. Preparing professional staff to care for cancer survivors. J Cancer Surviv. 2007;1:98-106.

11. Clark EJ, Stovall EL, Leigh S, Sui AL, Austin DK, Rowland JH. Imperatives for quality cancer care: access, advocacy, action and accountability. National Coalition of Cancer Survivorship, 1996:7-8.

12. Health Education Assets Library. Available at: http://www.healcentral. org/index.jsp. Accessed July 2009.

13. American Association of Medical Colleges MedEd Portal. Available at: http://services.aamc.org/30/mededportal/servlet/segment/mededpor tal/information/. Accessed July 2009

14. Ferrell BR, Virani R, Smith S, et al. The role of oncology nursing to ensure quality care for cancer survivors: a report commissioned by the National Cancer Policy Board and Institute of Medicine. Oncol Nurs Forum. 2003;30:E1-11.

15. Muss HB, Von Roenn J, Damon LE, et al. ASCO core curriculum outline. J Clin Oncol. 2005;23:2049-77.

16. Oncology Education Committee, Ideal oncology curriculum for medical schools, The Cancer Council Australia, 2007. Available at: http://www. cancer.org.au/File/PolicyPublications/IdealOncologyCurricDEC07.pdf. Accessed July, 2009. 